Dorin-Ion Dumitrascu

Cristin Olimpiu Morariu

Adela-Eliza Dumitrascu $\bowtie$

Doina Valentina Ciobanu

https://doi.org/10.21278/TOF.42108

ISSN 1333-1124

eISSN 1849-1391

\title{
RELIABILITY ESTIMATION OF TOWED GRADER ATTACHMENT USING FINITE ELEMENT ANALYSIS AND POINT ESTIMATION
}

\begin{abstract}
Summary
The paper presents an analysis of the reliability of front blade, rear blade and frame of the towed grader as well as experimental validation of the results obtained from the finite element analysis. The analyzed prototype was designed for maintenance and repair of forest roads and equipped with two types of blades for cleaning and levelling the ground surface. Lifetimes of towed grader attachments can be estimated with high accuracy using threeparameter Weibull distribution. The values of the location parameter $\gamma$ were determined by using the maximum values of the correlation coefficient, while the method of maximum likelihood was used for the point estimation of the parameters. Because higher values of the shape parameter had been obtained, the point estimation and estimation with confidence intervals of components lifetimes were performed. The analysis of the results indicates that the used assumptions may not fully take the complex stresses encountered in use into account.
\end{abstract}

Key words: $\quad$ towed grader, reliability estimation, finite element analysis (FEA), Weibull distribution, confidence interval

\section{Introduction}

An ambitious and rapidly growing rate of the earth moving machinery industry is achieved owing to the high performance construction machinery with complex mechanisms and the automation of the construction activities. Bulldozers, scrapers, graders, excavators and other machines are widely used for most arduous earth moving work in construction engineering. Thus, it is really necessary for the designers to provide not only equipment of maximum reliability but also of minimum weight and cost, keeping the design safe under all loading conditions by performing careful stress analyses of machines $[1,2]$.

Towed graders are designed for a variety of applications including earthworks for removing vegetation, grading, road building and maintenance, ditch and slope works, scarifying and snow removal $[3,4]$.

These types of machines are characterized by a good handling of an actively working body (blade) that is displaced horizontally, vertically and laterally. The maneuverability of the 
blade and the creation of the needed force for the blade to penetrate the soil are the main requirements imposed on the towed grader to ensure its operational performance [5].

Most of the studies on reliability estimation of grader structural components have focused on the finite elements analysis (FEA), [1, 6-10].

FEA is the most powerful technique for calculations of strength of the structures working under some known load and boundary conditions [2]. The implementation of the FEA makes the identification of weak components of towed grader attachments possible because a strength analysis is performed.

A case study on the analysis and simulation of shock resistance of a grader blade was carried out by Yongjun et al. [11]. The authors determined that a crack on a grader blade often occurred during an impact. In order to avoid this failure, shock resistance of the blade was analyzed and the characteristic curve of the shock resistance of the blade was also obtained based on different types of impact acceleration. They also studied the FEA model, impacts of different types of obstacles were transferred into impact forces, and the impact characteristics of the blade were acquired rapidly based on the dynamic explicit finite element method.

In this paper, we propose a design solution for towed grader attachments, i.e. for two blades designed for maintenance and repair of forest roads, including an estimation of the grader reliability and experimental validation of the results obtained from the FEA. The main working part of the grader blade is the front blade, to which auxiliary ripping teeth and a bulldozer front blade can be mounted. The front blade can be used either as embankment or ditch digging equipment, depending on the change of the working position. The FEA analysis enables us to determine levels of stress and deformation on the grader frame, the front blade and the rear blade and to estimate the product lifetime. Based on the FEA results and considering the performance specification, the duration of exploitation, as well as the design and technological factors, the reliability of the towed grader attachments has been estimated using the most suitable statistical model for such an analysis. The reliability of the front blade, the rear blade and the frame was estimated by using the three-parameter Weibull distribution. The objective was to estimate the distribution parameters by two methods: point estimation and estimation with confidence intervals.

\section{Design characteristics of the towed grader designed for maintenance of forest roads}

The prototype of the analyzed towed grader was designed and built by the Institute of Research and Forest Management Bucharest, Laboratory for Forest Works Mechanization. Its main technical characteristics are as follows (Fig. 1a):

- main dimensions: length: 2,000-2,200 mm, width: 2,200-2,500 mm, height: 900$1,000 \mathrm{~mm}$,

- weight: $550-600 \mathrm{~kg}$,

- angle of the blades: $0^{\circ}-30^{\circ}$,

- blade height: $540-560 \mathrm{~mm}$.

The front blade is made of steel sheet sleeve $8 \mathrm{~mm}$ thick in order to obtain the curvature for the transport of filler material. The blade has reinforcing ribs (gussets) at the back, arranged equidistant so as to stiffen the blade. At the bottom of the moldboard, there is a scraper knife made of manganese austenitic material with a relatively low hardness $(250 \mathrm{HB}$ Brinell units) with high wear resistance, commonly termed the Hadfield steel.

Due to heavy wear that they are subjected to, scraper blades are spare parts.

At the upper part of the blade and decentered from the axis of symmetry of the blade, a bracing tube is welded to the rod of the hydraulic cylinder which controls the rotation of the blade. Also, at the top there is a metal box with a screw of special design that fastens bearing 
bushes to the chassis. The special design screw mounted in the blade is fastened to the chassis with a nut and a cotter pin is inserted to prevent the nut from loosening.

The front blade has a length of 2,000 mm, which permits spreading and levelling the material in a single pass, which is completed by the second blade (the rear blade) arranged asymmetrically with respect to the front blade. This technological solution has been adopted to improve the load distribution on the two blades. In addition, the asymmetry to the attachment of the blades to the frame results in a working width of about $2,700 \mathrm{~mm}$ in the case when the blades are arranged perpendicular to the longitudinal axis of the chassis.

The rear blade has an identical design with the front blade, having the same kind of a longitudinal scraper knife (similar to the one on the front blade) at the bottom of the working area. The movement relative to the longitudinal axis is carried out separately by the first blade by means of the second hydraulic cylinder. It is possible that the grader works with one of the blades inclined at an angle and the second blade perpendicular to the direction of advance of the grader.

The blades are powered by two hydraulic cylinders. The blades work simultaneously with an overlap of 1,600 $\mathrm{mm}$ centered by the longitudinal axis of the chassis. In this manner, in a single pass of the grader, the blades, levelling the road surface, pass the surface twice. With the inclination of the blades operated by the hydraulic cylinders, the working width decreases with a sinusoidal projection, reaching the minimum value of $2,500 \mathrm{~mm}$.

In the case when a forest road is repaired with gravel it will be necessary to obtain parallelism between the equipment frame and the road surface that must be repaired.

\section{Finite element analyses of the subassembly of the towed grader}

A 3D model of a towed grader (Fig. 1a) was performed by using the Pro-Engineering software, widely used in design and mechanical engineering. In the $3 \mathrm{D}$ modelling only the components that have a structural role in the operation and the most unfavorable position of the two blades, i.e. when they rotate through 30 degrees relative to the transverse axis of the machine, were taken into account. The hydraulic cylinders, which tilt the blade, were not modelled, but were simulated directly in the Ansys Workbench.

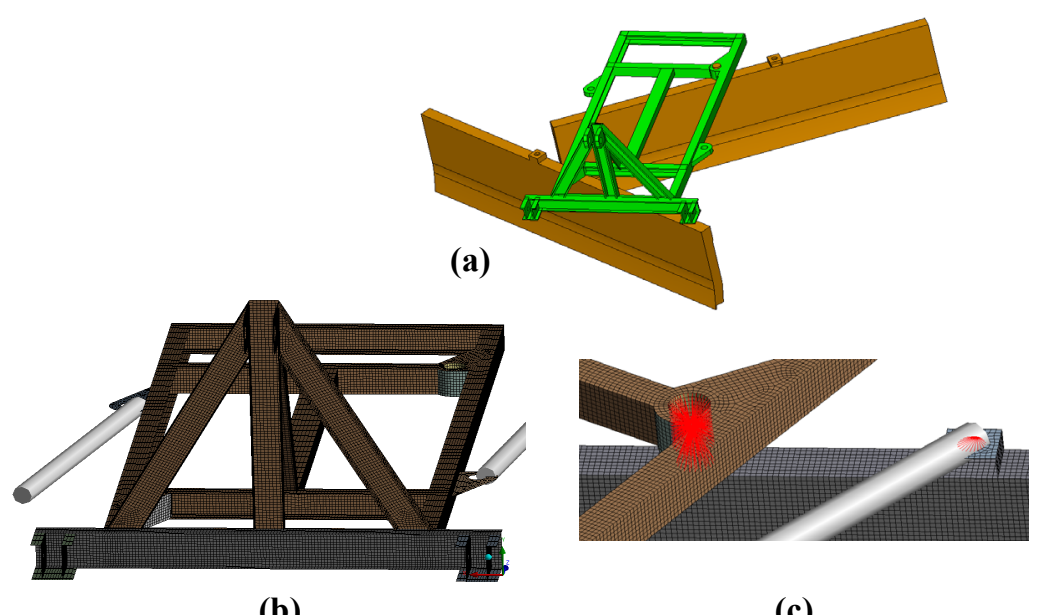

(b)

(c)

Fig. 1 Finite element modelling of the towed grader: (a) 3D model; (b) 2D towed grader frame; (c) the link between the blade and the frame and between the blade and the hydraulic cylinder

The FEA was performed by using the Ansys Workbench software. The 2D finite elements that simulate profiles and sheets as they are given in the model were assigned material properties including the thickness of each component. 
The towed grader structure is made of square profiles, $\mathrm{C}$ profiles and plates. On the front frame there are two mounting brackets and a mounting bracket subassembly of the upper link. This structure is welded, non-removable and simulated with shell-type elements (Fig. 1b). The links between the welded components are achieved by using common joints, located between the finite elements of the weld area. Shell type 2D finite elements were used to simulate the blade. The welded blade sheets were connected by common nodes between the finite elements of the weld area. The pin around which the front blade rotates to the grader frame was modelled with a rigid element, linked to the two components, the blade and the frame, which rotates freely around the axis of the pin (Fig. 1c). The hydraulic cylinder was simulated by using a deformable beam type 1D element, which preserved the cylinder section properties. The links with the blade, i.e. with the grader frame were made by using rigid elements fixed in all degrees of freedom (Figs. 1b and 1c).

The finite element modelling of the towed grader has taken the following into account: the numerical modelling is to be as close to actual operating conditions as possible, the quality of items and the number of nodes and elements result in a finite element mesh.

When the levelling blade is calculated, the blade geometry is a portion of a cylinder having a radius of $3,100 \mathrm{~mm}$, sectioned by two generators. The blade is considered to be embedded in the centre of the cylinder by means of a rigid member at its upper end. On the working surface of the blade the applied normal pressure is about $0.016727 \mathrm{MPa}$, representing a half of the traction force needed for the levelling process $(36000 \mathrm{~N})$.

For the purpose of obtaining the results from the numerical calculation that would be as close to reality as possible, all forces acting on the towed grader during operation will be taken into account (Fig. 2). The traction force produced by the tow tractor is $F_{\text {tot }}=36,000 \mathrm{~N}$ and it is exerted to each of the grader blade. When the structure is subjected to such stress, it was considered that the worst case is when each blade grader was charged with the same amount of material (ballast) over the whole surface. The force is applied normal to the working surface of the blade, angled at 30 degrees. Gravitational acceleration was applied to the whole system taking the grader mass into account. The constraints in the finite element model were all degrees of freedom, the clamping brackets and the mounting bracket subassembly of the upper link of the grader.

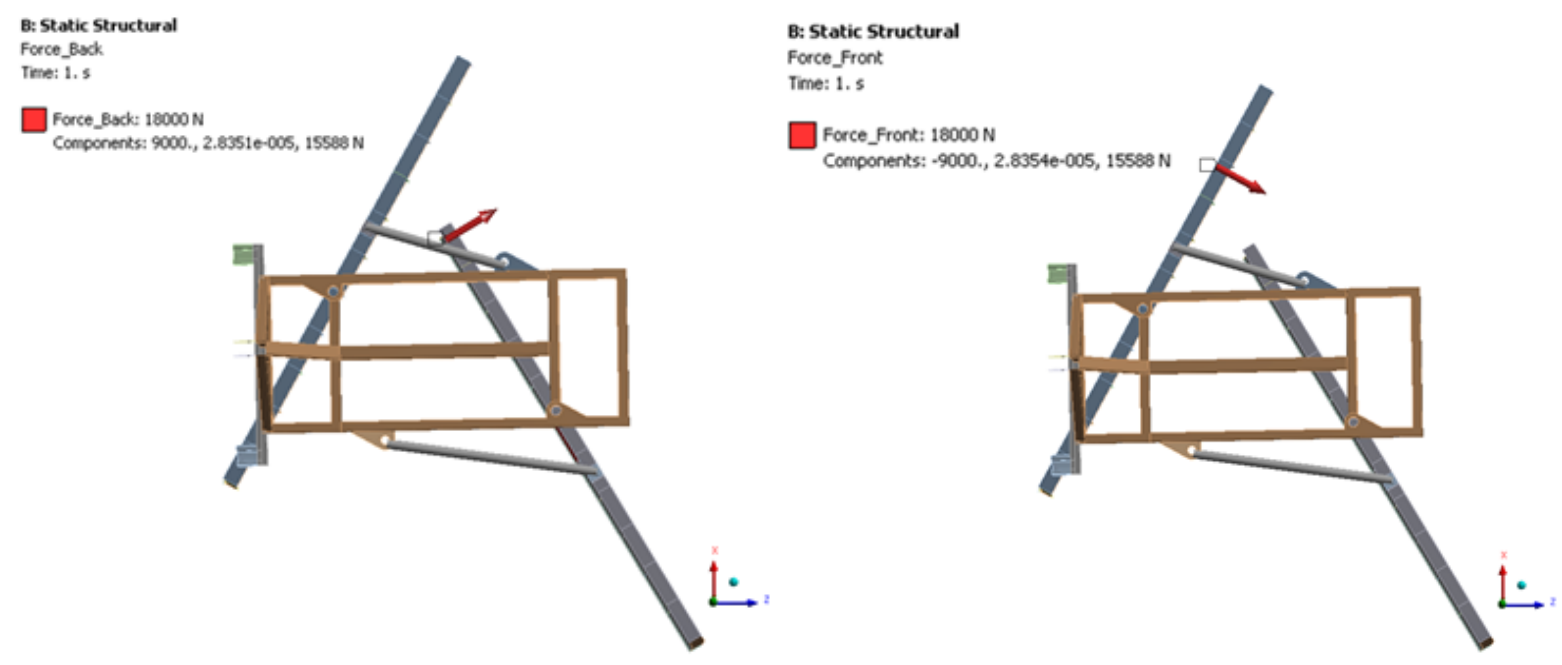

Fig. 2 The force decomposition in three directions of each blade 


\section{Reliability analysis of towed grader attachments}

In order to estimate lifetime of the towed grader attachments, in the first stage we identified the most suitable statistical model for such an analysis. In this respect, the Anderson-Darling concordance test was used, applied on experimental data, $y_{i}, i=\overline{1, n}$ considering four statistical distributions used in the reliability analysis (Fig. 3).

Applying this concordance test to the four cases, the statistic estimation of the following parameter is carried out as follows [12]:

$$
A_{n}^{2}=n \cdot \int_{-\infty}^{\infty} \frac{[Q(y)-F(y)]^{2}}{F(y) \cdot[1-F(y)]} \cdot d F(y) .
$$

The obtained value is a measure of the discrepancy between the empirical distribution, $Q(y)$, sampling values and the considered theoretical distribution, $F(y)$.

If, for the empirical distribution the relation is used:

$$
Q\left[y_{(i)}\right]=\left\{\begin{array}{lll}
0, & \text { for } & Y<y_{(1)} \\
\frac{1}{n}, & \text { for } & y_{(i)}<Y<y_{(i+1)}, \quad i=\overline{1, n-1}, \\
1, & \text { for } & Y>y_{(1)}
\end{array}\right.
$$

then, the Anderson-Darling test statistic results in [13]:

$$
A_{n}^{2}=-\sum_{i=1}^{n} \frac{2 \cdot i}{n} \cdot\left\{\ln F\left(y_{(i)}\right)+\ln \left[1-F\left(y_{(n+1-i)}\right)\right]\right\}-n .
$$

Using the experimental results obtained from the operation of the three attachments to the towed grader (the front blade, the rear blade and the frame), the calculated values of the Anderson-Darling statistics (Table 1) indicate that the Weibull distribution allows modelling of the lifetime of this equipment with the highest accuracy (Fig. 3).
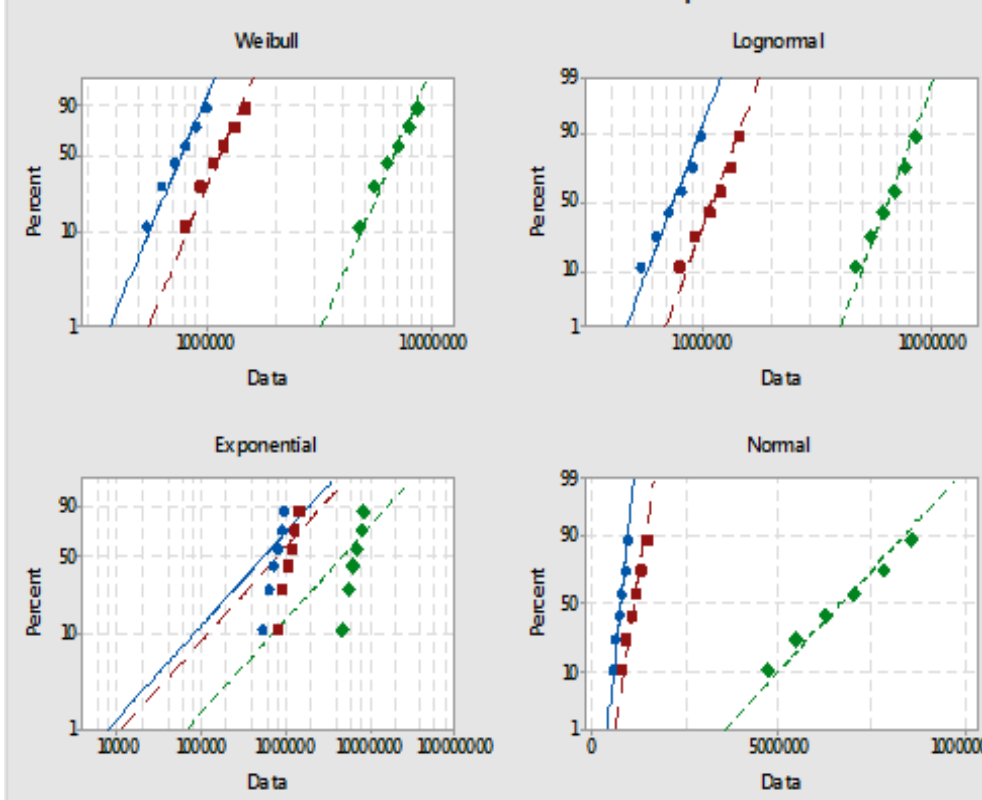
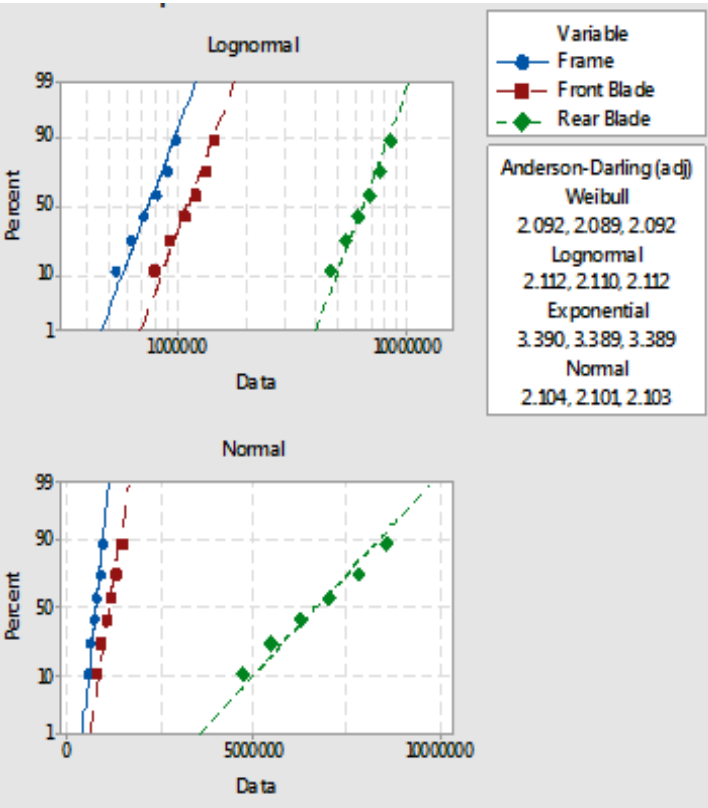

Fig. 3 Probability plot of the Anderson-Darling test for the frame, the front blade and the rear blade

The location parameter $\gamma$ is estimated by using the correlation coefficient method and minimum lifetimes are determined experimentally (Table 2). 
D.-I. Dumitrascu, C. O. Morariu,

A.-E. Dumitrascu and D. V. Ciobanu
Reliability Estimation of Towed Grader Attachment Using Finite Element Analysis and Point Estimation

Table 1 The Anderson-Darling statistics

\begin{tabular}{|c|c|c|c|}
\hline \multirow{2}{*}{ Distribution } & \multicolumn{3}{|c|}{ Anderson-Darling statistic values, $A_{n}^{2}$} \\
\cline { 2 - 4 } & Frame & Front Blade & Rear Blade \\
\hline Weibull & 2.092 & 2.089 & 2.092 \\
\hline Log-normal & 2.112 & 2.110 & 2.112 \\
\hline Exponential & 3.390 & 3.389 & 3.389 \\
\hline Normal & 2.104 & 2.101 & 2.103 \\
\hline
\end{tabular}

The estimation method consists of determining the location parameter values, $\gamma$, under maximum conditions of the correlation coefficient values [14].

Table 2 The parameter estimation

\begin{tabular}{|c|c|c|c|}
\hline \multirow{2}{*}{ Coefficient } & \multicolumn{3}{|c|}{ Towed grader } \\
\cline { 2 - 4 } & Frame & Front Blade & Rear Blade \\
\hline$\gamma$ & 315226.979 & 460147.983 & 2746288.329 \\
\hline$\rho$ & 0.99821 & 0.99839 & 0.99821 \\
\hline
\end{tabular}

The results shown in Table 2 were obtained by using an application in the Mathcad software. Knowing the values of the location parameter, the obtained values are twoparameter Weibull distributed (Table 3).

Table 3 Lifetime estimation of the frame, the front blade and the rear blade.

\begin{tabular}{|c|c|c|c|}
\hline \multirow{2}{*}{ Issue } & \multicolumn{3}{|c|}{ Lifetime (cycle), $x_{i}, i=\overline{1, n}$} \\
\cline { 2 - 4 } & Frame & Front Blade & Rear Blade \\
\hline 1 & 224773.02 & 339852.02 & 1953711.67 \\
\hline 2 & 314773.02 & 472852.02 & 2733711.67 \\
\hline 3 & 404773.02 & 609852.02 & 3523711.67 \\
\hline 4 & 494773.02 & 739852.02 & 4303711.67 \\
\hline 5 & 584773.02 & 869852.02 & 5083711.67 \\
\hline 6 & 674773.02 & 1009852.02 & 5873711.67 \\
\hline
\end{tabular}

In order to estimate the reliability and unreliability functions, the probability density function and the hazard rate of the front blade, the rear blade and the frame of the towed grader, the statistical processing of experimental data allows us to determine the statistical parameters of distribution using specialized functions from the Minitab [15] and Mathcad software.

The point estimation method used is maximum likelihood. The estimated values of the shape and scale parameters of the two-parameter Weibull distribution are obtained as a solution to the equation system $[12,14,16-21]$.

Because the sample size is very small, asymptotical properties of the maximum likelihood estimators cannot be applied in this case, and the estimations with confidence intervals were calculated on the basis of two random variables, independent of the sample size $(n)$ and the type of test $(n=r)$ for the complete test. The point estimation and the estimation with confidence intervals for the Weibull distribution parameters were determined based on the estimated lifetime presented in Table 3 and are shown in Table 4. The confidence level used is $1-\alpha=0.95$ and corresponding values of the random variables $v(r, n)$ and $k(r, n)$ were taken from [14]. 
Table 4 Parametric estimation of $\beta$ with confidence interval

\begin{tabular}{|l|c|c|c|}
\hline \multicolumn{1}{|c|}{ Parameter } & Frame & Front Blade & Rear Blade \\
\hline$\beta$ & 3.312 & 3.345 & 3.308 \\
\hline$\beta$ unbiased mean estimate & 2.475 & 2.500 & 2.472 \\
\hline$\beta$ unbiased median estimate & 2.786 & 2.814 & 2.782 \\
\hline$\beta_{\mathrm{L}}$ & 1.125 & 1.137 & 1.124 \\
\hline$\beta_{\mathrm{U}}$ & 5.221 & 5.273 & 5.214 \\
\hline$\eta$ & 503199.504 & 753268.187 & 4377022.514 \\
\hline$\eta$ unbiased mean estimate & 509353.318 & 762387.877 & 4430623.371 \\
\hline$\eta$ unbiased median estimate & 509302.572 & 762312.678 & 4430181.362 \\
\hline$\eta_{\mathrm{L}}$ & 349418.523 & 524968.199 & 3037882.11 \\
\hline$\eta_{\mathrm{U}}$ & 745295.925 & 1111319.82 & 6486304.749 \\
\hline
\end{tabular}

Fig. 4 shows a comparison between values of the reliability indicators of the three attachments of the towed grader in the Weibull probability network.

High values of the shape parameters $\beta=3.308, \beta=3.312$ and $\beta=3.345$ indicate that the normal distribution for reliability modelling can be used. The same conclusion can be drawn from the Anderson-Darling statistics analysis, as shown in Fig. 4.

The point estimation and the estimation with confidence intervals for normal distribution parameters were determined based on the estimated lifetime given in Table 3 and they are shown in Table 5. The confidence level used is $1-\alpha=0.95$.

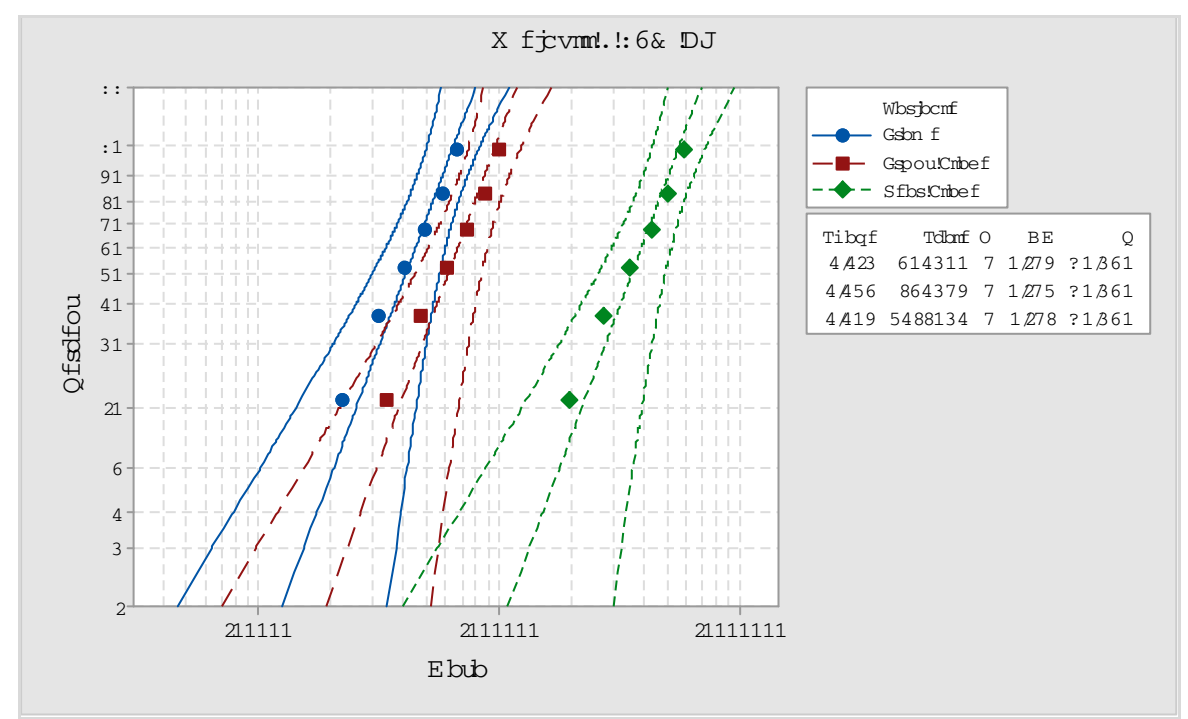

Fig. 4 Probability plot of the frame, the front blade and the rear blade for the Weibull distribution

Table 5 Parametric estimation of $\mu$ with confidence interval

\begin{tabular}{|l|l|l|l|}
\hline Parameter & \multicolumn{1}{|c|}{ Frame } & \multicolumn{1}{c|}{ Front Blade } & \multicolumn{1}{c|}{ Rear Blade } \\
\hline$\mu$ & 765000.00 & 1133833.33 & 6658333.33 \\
\hline$\mu_{\mathrm{L}}$ & 588301.71 & 871801.70 & 5119652.86 \\
\hline$\mu_{\mathrm{U}}$ & 941698.29 & 1395864.97 & 8197013.80 \\
\hline$\sigma$ & 168374.5824 & 249688.1388 & 1466198.031 \\
\hline$\sigma_{\mathrm{L}}$ & 105100.7617 & 155857.3343 & 915212.544 \\
\hline$\sigma_{\mathrm{U}}$ & 412957.8561 & 612388.622 & 3596017.801 \\
\hline
\end{tabular}


Fig. 5 shows a comparison between values of the reliability indicators of the three attachments of the towed grader with confidence interval in a network having normal probability distributions.

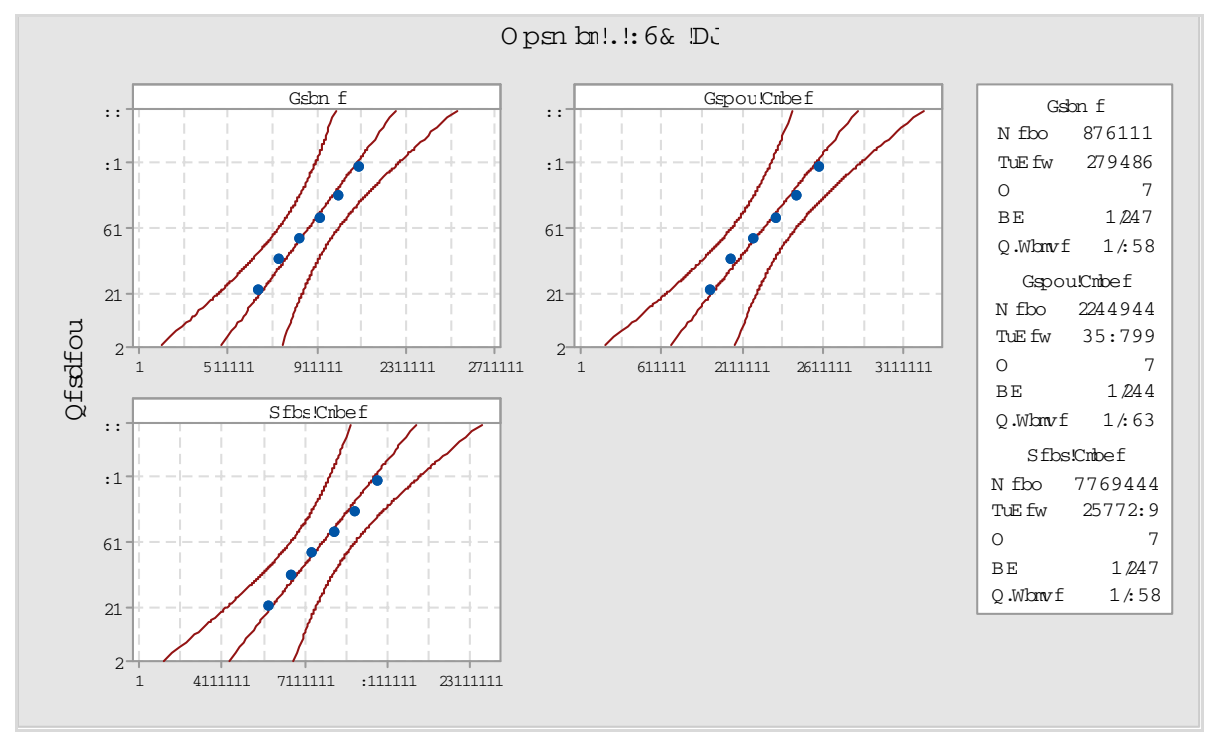

Fig. 5 Normal probability plot of the frame, the front blade and the rear blade

\section{Results and discussion}

The results obtained from the finite element calculations performed for the prototype of a levelling blade focus on deformation and stress levels. Since the blade is a structure made of welded steel plates, the assumptions for the analytical calculation were simplified. The finite element calculation was modelled based on the existing levelling blade and it took all the components, such as tables and gussets behind the blade, into account. Modern methods of calculation, widely used in the machine building industry and beyond, were used to check the blade size calculation. Due to the curvature of the blade, forces acting on the blade were broken down in each direction.

The calculated maximum displacement on the levelling blade is $0.4 \mathrm{~mm}$ and is located at the bottom of the blade, as shown in Fig. 6a. Also, blade positions (undistorted or deformed) are presented, indicating the deformation gradient (scaling factor 100). The maximum value of the equivalent stress $(88.7 \mathrm{MPa})$ is obtained on the back of the blade, near the gusset-plate weld zone. It is noted that the stress value does not exceed the yield strength (365 MPa) of the material (Fig. 6b). From Figs. 6c and 6d it can be seen that the main stress acting on the blade is compressive stress. It is caused by the pressure applied to the blade surface, which compresses the gussets that are located behind the blade. For the calculation of the levelling blade a safety factor greater than 2, which is calculated by the finite element method using the ANSYS Workbench, is required. As can be seen in Fig. 6e, the minimum value of the safety factor is 4 . The safety factor value is obtained in the area near the gussetback blade plate weld zone. Forces acting on the two blades of the towed grader developing reaction forces in each direction are presented in Fig. $6 \mathrm{f}$. 


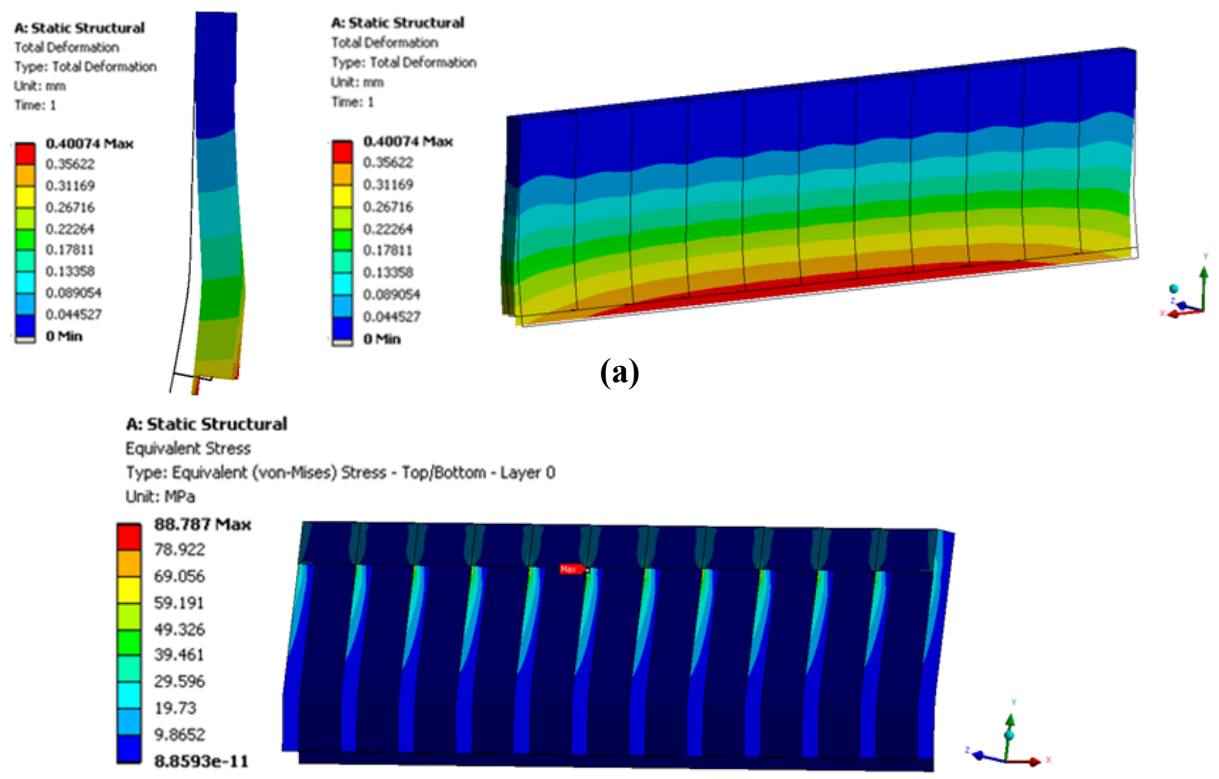

(b)

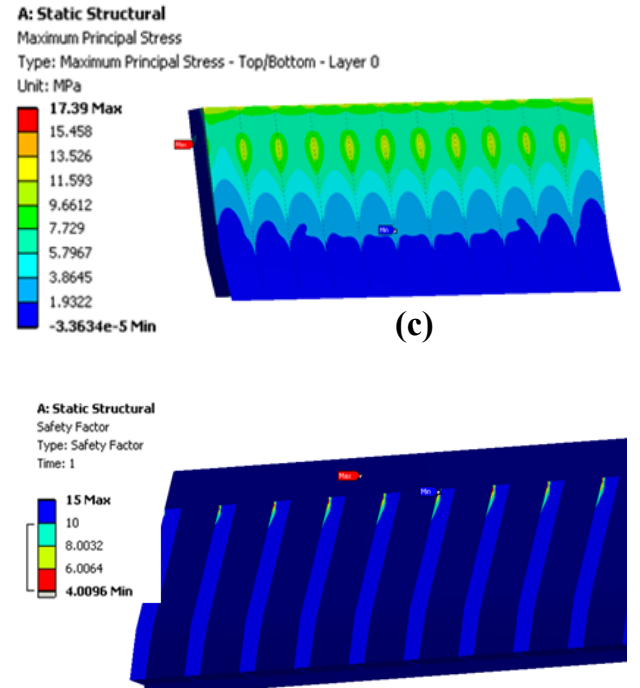

(e)

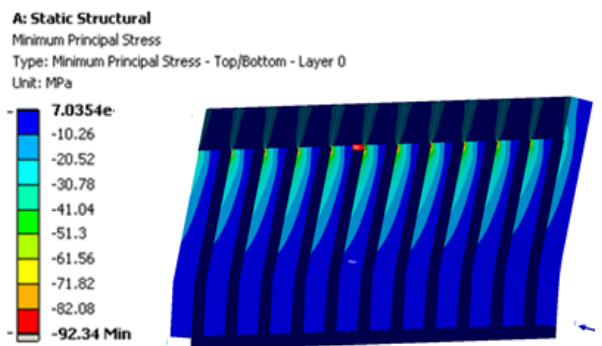

(d)

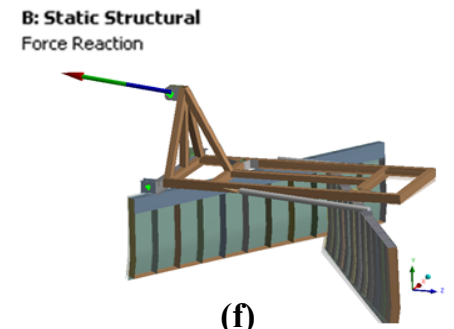

(f)

Fig. 6 Equivalent von Mises stresses, distribution of the safety factor and total reaction force

Due to the fact that the two blades are angled in opposite directions, the resultant force in the $X$ direction is cancelled. The reaction force obtained in the $Y$ direction is given by the mass of the vehicle and by the force component that causes stress on these two blades having the same direction. The higher force acts around the $Z$ axis, in the direction of the movement of the tractor. The total resultant force is close to the maximum value of the towing force. The difference in the calculated total force in the extent from $31,342 \mathrm{~N}$ to $36,000 \mathrm{~N}$ can occur due to nonlinearities appeared in the model, numerical calculation errors specific to the calculation method, but also because of the way the connections between the components of the finite element model are made.

The maximum total displacement calculated on the towed grader is $46.6 \mathrm{~mm}$ and was located at the bottom of the blades, the point farthest from the grader blade attachment to the frame (Fig. 7). Fig. 7 shows the grader deformation in side view where the real grader deformation can be seen and the undistorted position is illustrated as wireframe on an enlarged scale of 5:1. Also, the frame displacement value is $26.3 \mathrm{~mm}$. 


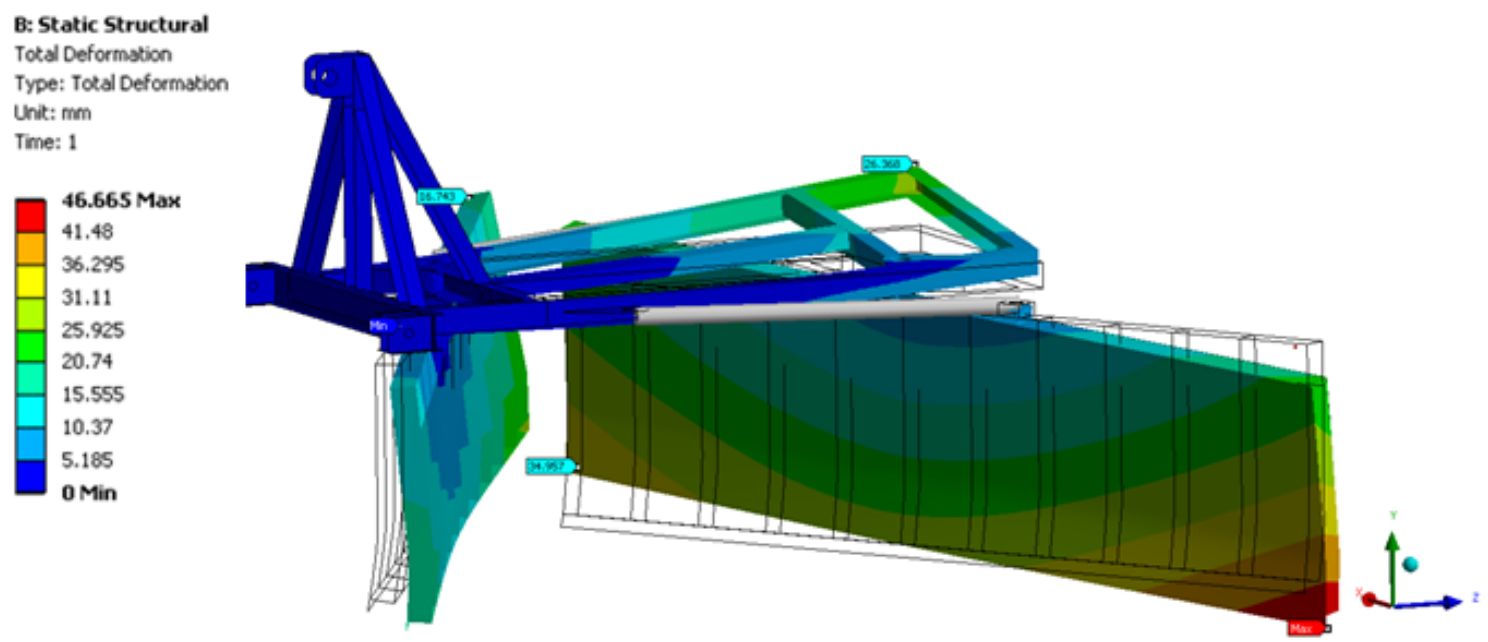

Fig. 7 Total shift of the towed grader

Von Mises equivalent stresses on the towed grader are shown in an overview in Fig. 8. The maximum stress $(767 \mathrm{MPa})$ is obtained in the area in which the frame is welded to the plates forming a rotating hitch of the tilting blades (Fig. 8a). These values of stresses in the weld areas are not real, because in these areas, due to the transformations of the welded material during welding, mechanical properties of materials change. For this reason, the reading is made at a distance equal to the size of the weld. The real value of the maximum equivalent stress is about $376 \mathrm{MPa}$, measured in the area in which the frame is welded to plates forming the rotating hitch used for tilting the front blade (Fig. 8b). In this weld area the equivalent stress is about $305 \mathrm{MPa}$ (Fig. 8c). In Figs. 8d and 8e the equivalent stress distribution on the two blades is shown. Maximum stresses are located near welds, in the middle part of the blade, right near the rotation couplings. Thus, on the front blade, the maximum stress is approximately $433 \mathrm{MPa}$ (Fig. 8d) and on the rear blade it is about 374 MPa (Fig. 8e).

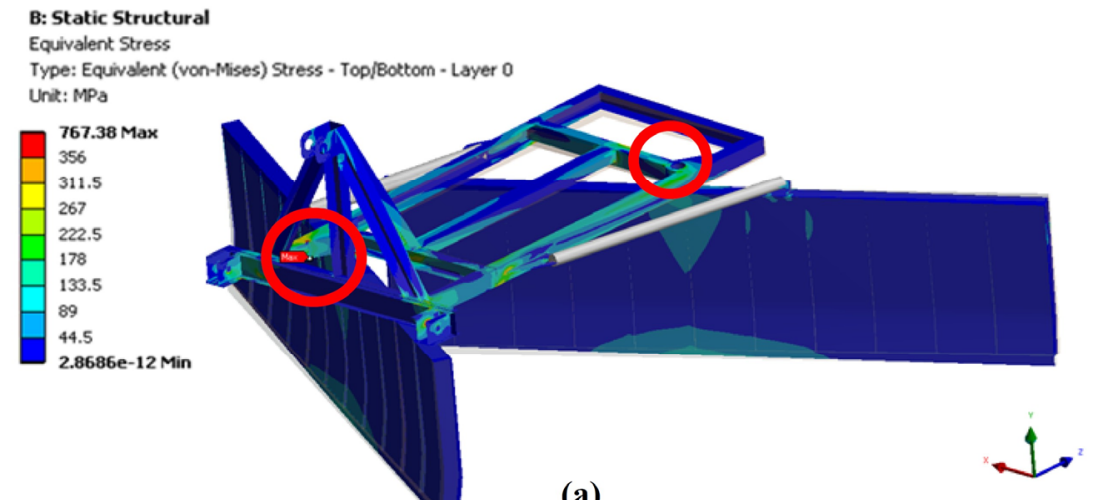

(a)

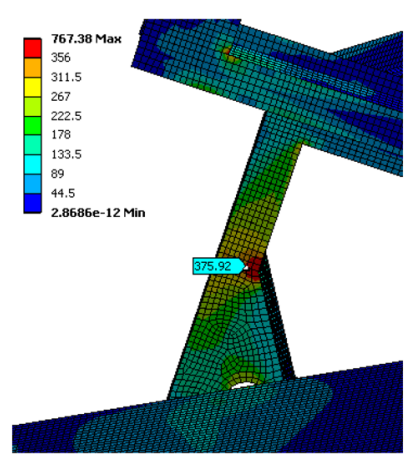

(b)

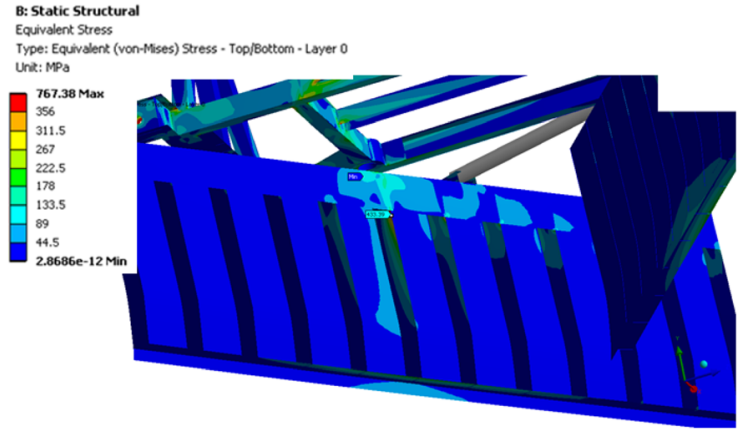

(d) 


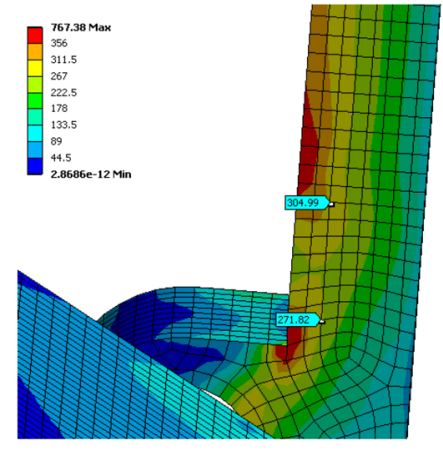

(c)

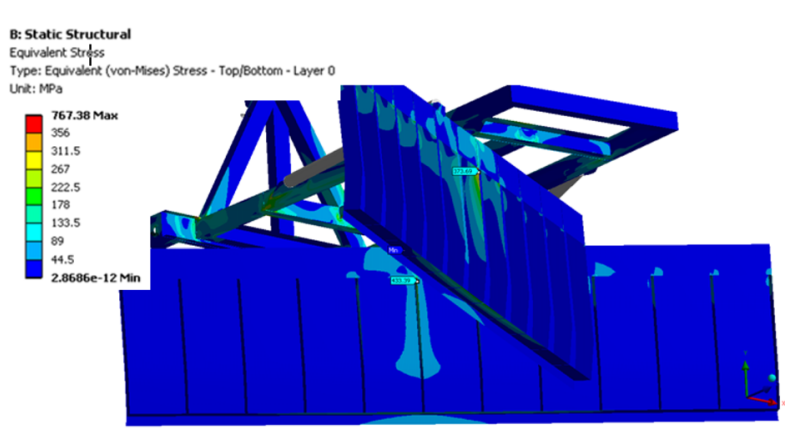

(e)

Fig. 8 Von Mises equivalent stress: (a) overview; (b) and (c) details in weld areas; (d) front blade; (e) rear blade

In terms of static loads acting on the towed grader, the maximum obtained stresses exceed the yield stress of material $(356 \mathrm{MPa})$, but are below the breaking point of the material $(441 \mathrm{MPa})$. Thus, the maximum stress on the grader frame is $376 \mathrm{MPa}$, on the front blade it is $433 \mathrm{MPa}$ and on the rear blade it is $374 \mathrm{MPa}$. These results indicate that during operation or after a limited period of time the towed grader can undergo permanent plastic deformation without reaching the breaking point. Also, the results obtained from the durability calculation in the marked areas are synthetically presented. The minimum lifetime is about $5.4 \mathrm{e} 5$ cycles and the critical area is on the front side of the frame, in the area in which the frame is welded to the plates that form the rotating hitch for tilting the blade. The front levelling blade has a minimum life of $8 \mathrm{e} 5$ cycles and this refers to the areas in which the gussets are welded to the plates which form the blade. Minimum lifetime of the rear blade is $4.7 \mathrm{e} 6$ cycles.

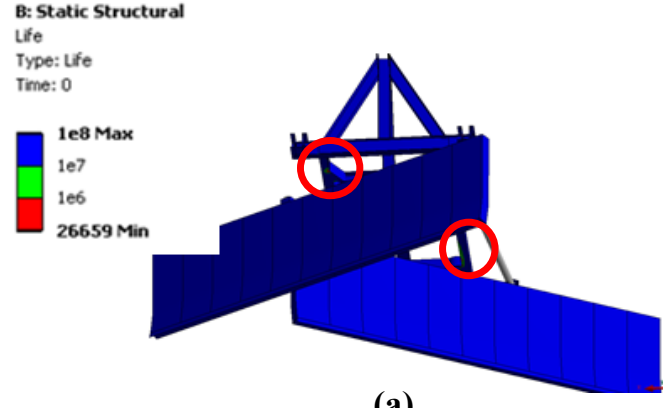

(a)

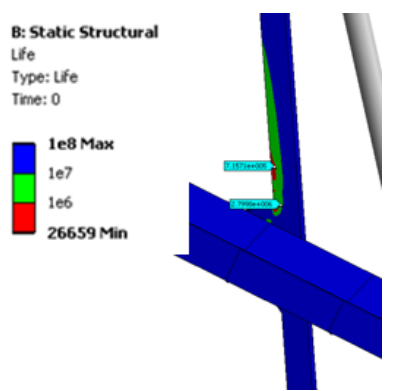

(c)

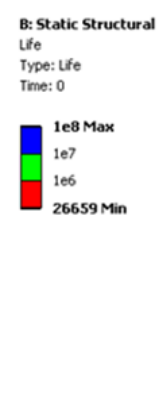

(b)
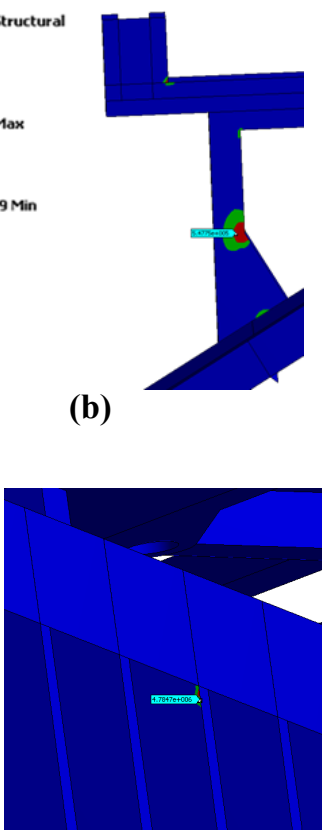

(e)

Fig. 9 Estimated lifetime: (a) general view; (b) and (c) area in which the frame is welded to plates forming rotating hitch for tilting two blades; (d) lifetime of the front blade; (e) lifetime of the rear blade.

The reliability of the towed grader subassemblies can be modelled by using the Weibull distribution model. In Table 6 and Fig. 10 analytical expressions of reliability functions for the three analyzed subassemblies are specified and values of the main reliability indicators are estimated based on the experimental results collected from the operation of these attachments. The value of the location parameter $\gamma$ indicates the minimum lifetime of each subassembly, 
D.-I. Dumitrascu, C. O. Morariu, A.-E. Dumitrascu and D. V. Ciobanu
Reliability Estimation of Towed Grader Attachment Using Finite Element Analysis and Point Estimation

estimated in real operating conditions. Reliability distribution plots for the frame, the front blade and the rear blade are presented in Fig. 10.

Table 6 Reliability indicators

\begin{tabular}{|l|c|c|c|c|}
\hline \multirow{2}{*}{ Subassembly } & \multicolumn{4}{|l|}{ The main reliability indicators } \\
\cline { 2 - 5 } & $R(t)$ & $\gamma$ & $\mu$ & $\sigma$ \\
\hline Frame & $e^{-\left(\frac{x-315227}{503200}\right)^{3.312}}$ & 315227.0 & 765000.0 & 168374.6 \\
\hline Front blade & $e^{-\left(\frac{x-460148}{753268}\right)^{3.345}}$ & 460148.0 & 1133833.3 & 249688.1 \\
\hline Rear blade & $e^{-\left(\frac{x-2746288}{4377023}\right)^{3.308}}$ & 2746288.0 & 6658333.3 & 1466198.0 \\
\hline
\end{tabular}

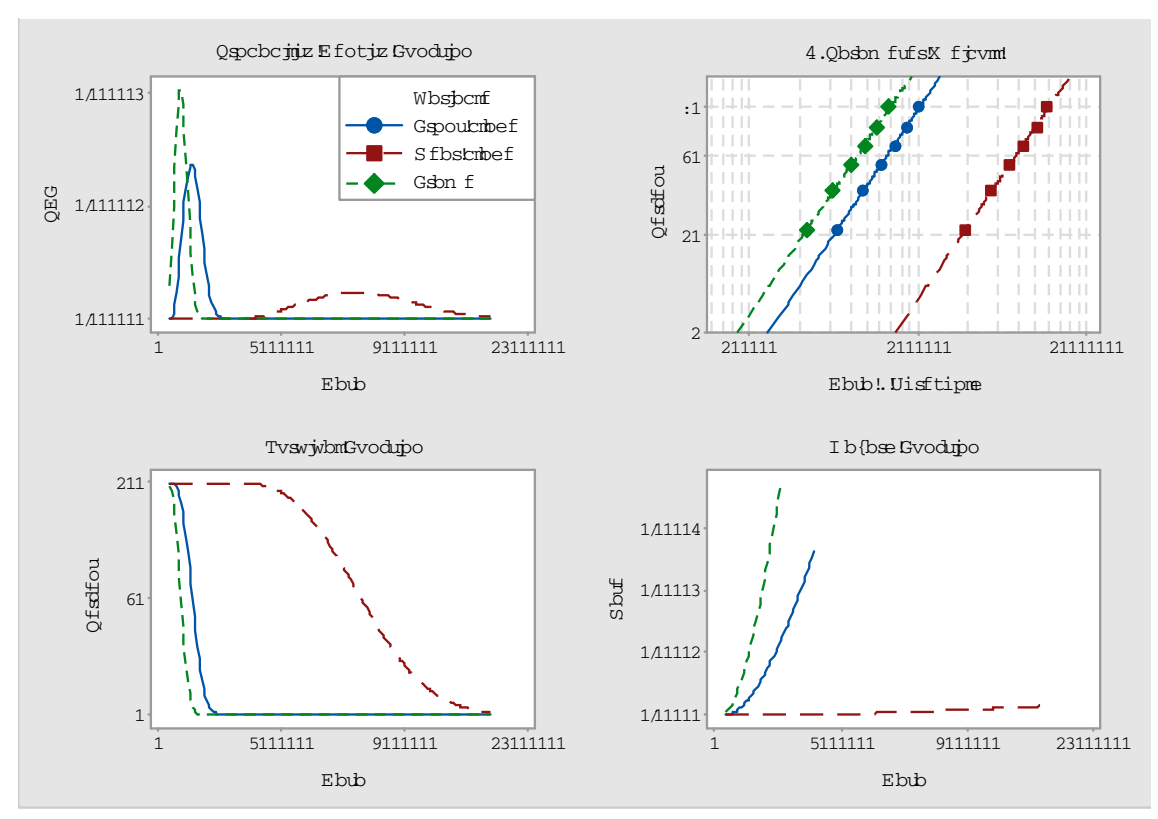

Fig. 10 Reliability distribution overview plot for front blade, rear blade and frame

\section{Conclusions}

In this paper, a reliability analysis of a prototype of a towed grader equipped with two blades and designed for maintenance and repair of forest roads is presented. Lifetime of the front blade, the rear blade and the frame was estimated and the FEA was validated through experimental studies. Based on the performed FEA modelling on the towed grader attachments, the following conclusions can be drawn:

- The maximum displacement obtained on the towed grader is $46.6 \mathrm{~mm}$; on the rear blade it was obtained on the corner farthest from the point of rotation;

- The maximum stress obtained on the frame is $376 \mathrm{MPa}$, and it is located in the area in which the frame is welded to the plates forming the torque needed for the inclination of the blade. On the front levelling blade, the maximum stress is 433 $\mathrm{MPa}$, and on the rear levelling blade the maximum stress is $374 \mathrm{MPa}$. The stress values obtained on the towed grader exceed the material yield strength $(356 \mathrm{MPa})$, but they are lower than its breaking limit (441 MPa);

- The determined minimum lifetime is 5.4e5 lifecycles in the area in which the frame is welded to the plates forming the torque needed for the inclination of the blade. On 
the front levelling blade, the lifetime is $8 \mathrm{e} 5$ cycles. These values do not fit the theory of fatigue which states that if the number of cycles exceeds $1 \mathrm{e} 6$, lifetime is unlimited. On the rear levelling blade, lifetime amounts to $4.7 \mathrm{e} 6$ cycles, which exceeds the duration of $1 \mathrm{e} 6$ cycles, and this is not a problem as long the lifetime complies with the stress cycle determined by the calculation.

The reliability analysis carried out for the towed grader attachments, based on the data collected from actual operating conditions allows us to draw the following conclusions:

- Reliability modelling of high accuracy can be achieved when the three-parametric Weibull distribution model is used;

- The value of the estimated minimum lifetime in actual operating conditions is lower than the value determined by the FEA method. These results indicate that the made assumptions may not have fully taken the complex stresses encountered in use into account.

- From Fig. 4 it can be concluded that the reliability values of the frame and the blade assemblies are close to each other, whereas the reliability value of the rear blade is much higher compared to the first two attachments.

- A high value of the shape parameter allows us to use normal distribution in the reliability analysis. This has offered the possibility of point estimation and estimation with confidence intervals of the average lifetime of the three component systems, as well as the estimation of the standard deviation of their lifetimes.

- Knowing the parameter values of the statistical distribution and the values of the main reliability indicators allows us a more useful approach to conducting preventive maintenance activities and their realistic planning.

\section{Acknowledgement}

The authors are grateful to the Transilvania University of Brasov for financial support. The analyzed equipment was provided by I.C.A.S. Bucharest and we would like to thank for their support and participation during data collection.

\section{REFERENCES}

[1] Motka, C. P. and Momin, R. I. (2015). Development of backhoe machine by 3-D modelling using CAD software and verify the structural design by using finite element method. International Journal for Innovative Research in Science \& Technology 8, 49-52.

[2] Patel, B. P. and Prajapati, J. M. (2011). A review on FEA and optimization of backhoe attachment in hydraulic excavator. International Journal of Engineering and Technology 3, 505-511.

[3] Hawthorne Cat (2015). Cat Motor Graders www.hawthornecat.com/cat_motor_graders

[4] TEREX (2015). Heavy duty motor graders. Motor graders product range, www.terex.com/construction/en/idc03/groups/webcontent/@web/@con/documents/web_content/ucm03_ 081012.pdf

[5] Debeleac, C. and Nastac, S. (2012). Comparative analysis between operational performances of motor grader equipment's. The Annals of "Dunarea De Jos" University of Galati-Mechanical Engineering XIV, 87-90.

[6] Meck, K.-D. and Zhu, G. (2008). Improving mechanical seal reliability with advanced computational engineering tools. Part 1: FEA. Sealing Technology 1, 8-11, https://doi.org/10.1016/S13504789(08)70023-0

[7] Gaspar, B., Naess, A., Leira, B. J. and Guedes Soares C. (2011). Efficient system reliability analysis by finite element structural models. In ASME 30 ${ }^{\text {th }}$ International Conference on Ocean, Offshore and Arctic Engineering: Structures, Safety and Reliability 2, 693-702. https://doi.org/10.1115/OMAE2011-49950

[8] Bing, L., Meilin, Z. and Kai, X. (2000). A practical engineering method for fuzzy reliability analysis of mechanical structures. Reliability Engineering and System Safety 67, 311-315. 
D.-I. Dumitrascu, C. O. Morariu,

A.-E. Dumitrascu and D. V. Ciobanu
Reliability Estimation of Towed Grader Attachment Using Finite Element Analysis and Point Estimation

[9] Nayak, A. O., Ramkumar, G., Manoj, T., Kannan, M. A., Manikandan, D. and Chakravarthy, S. (2012). Holistic design and software aided finite element analysis (FEA) of an All-Terrain Vehicle. Journal of Mechanical Engineering Research 4, 199-212. https://doi.org/10.5897/JMER12.009

[10] Kiam Beng Yeo, Wai Heng Choong and Wen Yen Hau. (2014). Prediction of propeller blade stress distribution through FEA. Journal of Applied Sciences 14, 3046-3054. https://doi.org/10.3923/jas.2014.3046.3054

[11] Yongjun, P., Liang, H., Qiliang, W. and Mingmin, C. (2010). Dynamic impact response analysis and simulation on grader blade. In International Conference on Mechanic Automation and Control Engineering (MACE), Wuhan, 6001-6004, https://doi.org/10.1109/MACE.2010.5536846

[12] Montgomery, D. C. and Runger, G. C. (2011). Applied statistics probability engineers. 5th ed. NewYork: John Wiley \& Sons, Inc.

[13] NIST (2013). Anderson-Darling Test Engineering Statistics Handbook, www.itl.nist.gov/div898/handbook/eda/section3/eda35e.htm

[14] Morariu, C. O. (2010). Probabilities and applied statistics. Vol. I., Transilvania University Publishing House, Brasov.

[15] Frost, J. (2013). How to identify the distribution of your data using Minitab, http://blog.minitab.com/blog/adventures-in-statistics/how-to-identify-the-distribution-of-your-data-usingminitab

[16] Montgomery, D. C., Runger, G. C. and Hubele, N. F. (2011). Engineering statistics. 5th ed. New-York: John Wiley \& Sons, Inc.

[17] Stodola, J. and Stodola, P. (2009). Operation reliability and diagnostics of mechanical systems. Transactions of Famena 33(1), 47-56

[18] Murthy, D. N. P., Xie, M. and Jiang, R. (2004). Weibull Models. Wiley Series in Probability and Statistics, New Jersey: John Wiley \& Sons.

[19] Bartkute, V. and Sakalauskas, L. (2008). The method of three-parameter Weibull distribution estimation. Acta et Commentationes Universitatis Tartuensis de Mathematica 12, 65-78.

[20] Comandini, M., Olmi, G. and Freddi A. (2007). Fatigue performance of shot-peened gears investigated by experimental and numerical methods. Transactions of Famena 31(2), 1-10.

[21] Nagatsuka, H., Kamakura, T. and Balakrishnan, N. (2013). A consistent method of estimation for the three-parameter Weibull distribution. Computational Statistics \& Data Analysis 58, 210-226, https://doi.org/10.1016/j.csda.2012.09.005

Submitted: $\quad 23.11 .2016$

Accepted: $\quad 09.3 .2017$

\author{
Dorin-Ion Dumitrascu \\ Cristin Olimpiu Morariu \\ Adela-Eliza Dumitrascu \\ (corresponding author) \\ dumitrascu_a@unitbv.ro \\ Transilvania University of Brasov, \\ Department of Manufacturing \\ Engineering, 29 Eroilor Street, \\ 500068 Brasov, Romania \\ Doina Valentina Ciobanu \\ Transilvania University of Brasov, \\ Faculty of Wood Engineering, \\ 29 Eroilor Street, \\ 500068 Brasov, Romania
}

